Available online on 15.10 .2020 at http://jddtonline.info
Open Access to Pharmaceutical and Medical Research
(C) 2011-18, publisher and licensee JDDT, This is an Open Access article which permits
unrestricted non-commercial use, provided the original work is properly cited

Open Access

Research Article

\title{
A Prospective Observational Studies on Drug Utilization Evaluation and Rational Use of Corticosteroids in Tertiary Care Hospital
}

\author{
Syeda Masarrath Unissa, Sana Kareem, Sumaiya Faheem Ahmed, Syed Imran Ul Haq, S Ahmedullah \\ Hussaini Quadri
}

Dept. of Pharmacy Practice. MESCO College of Pharmacy, Hyderabad, Telangana, India

\begin{abstract}
Background: Corticosteroids are widely prescribed Drugs in Hospitals, forming a part of standard treatment of modern medicine for a wide range of diseases, associated with inflammation and immune activation. Apart from beneficial effects they also produce number of adverse effects. In the present study, Prospective Observational studies on DUE (Drug utilization evaluation) and rationality of Corticosteroids has been Performed.

Objectives: To Investigate the Drug utilization evaluation, Prescription pattern and Rationality of corticosteroids in various department of tertiary care teaching hospital.

Methodology: A prospective observational study was conducted on 100 patients receiving corticosteroids in the various departments of Osmania general Hospital, Hyderabad. Patients prescribed corticosteroids therapy was included in the study. Exclusion of those patients with age less than 18, psychiatric disease, pregnant women and patients not willing to sign on consent form.

Result: This study included 100 Patients out of which 68 were Male and 32 were female. In Age wise distribution, 15 Patients prescribed with corticosteroid in age group 18-28 years, 20 patients in 29- 38 years, 12 in 32-48 years, 16 in $49-58$ years, 22 in $59-68$ years, 11 in $69-78$ years and 4 in above 80 years. This data showed that commonly male populations are more prone to diseases. As per the demographic data our finding shows that Budesonide was the most frequent prescribed corticosteroid (31.75\%) followed by Hydrocortisone (26.19\%), Dexamethasone (15.08\%), Prednisolone 13.49\%, Betamethasone (7.94\%), Methyl prednisolone (5.56\%).

Out of 100 prescriptions total 10 ADRs and 25 Drug interactions were detected in this study. The majority of drug interactions were minor 24 followed by major 1 .

Conclusion: The Prescription pattern of corticosteroids was found to be rational as there is no Major drug interaction. Commonly geriatric population was more prone to diseases, for which steroids were used. Hence close observation is required to ensure safety, effectiveness and well-balanced therapeutic management with corticosteroids, both patients and prescribers should be more aware of the appropriate dose, dosage regimen, Drug - Drug interactions, ADRs and overall guidelines for corticosteroids prescribing.
\end{abstract}

Keywords: Corticosteroids, Drug utilization evaluation, Prescription pattern.

Article Info: Received 19 July 2020; $\quad$ Review Completed 05 Sep 2020; $\quad$ Accepted 11 Sep 2020; $\quad$ Available online 15 Oct 2020

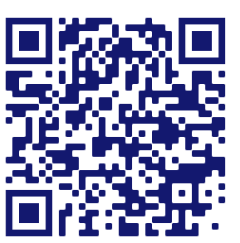

Cite this article as:

Unissa SM, Kareem S, Ahmed SF, Ul Haq SI, S Quadri AH, A Prospective Observational Studies on Drug Utilization Evaluation and Rational Use of Corticosteroids in Tertiary Care Hospital, Journal of Drug Delivery and Therapeutics. 2020; 10(5-s):119-126 http://dx.doi.org/10.22270/jddt.v10i5-s.4352

Syed Imran Ul Haq, Dept of Pharmacy Practice, Mesco College of Pharmacy, Hyderabad, Telangana, India

\section{INTRODUCTION}

The clinical practice of assessing specific drugs at appropriate and equal intervals to evaluate the drug concentration in the bloodstream through the course of therapy is therapeutic drug monitoring. This also helps in formulating an individual dosage regimen in patients with concomitant drug therapy which enhances the treatment outcome of the patients. 1
Most of the drugs don't require monitoring but drugs with narrow therapeutic windows, drugs that elicit pharmacokinetic variability and drugs that have a higher probability to cause adverse effects at therapeutic doses show a necessity to be monitored. ${ }^{1}$

TDM is based on the belief that there is a significant relationship between the dose and plasma concentration of the drug and also between the concentration of the drug and its therapeutic effect. ${ }^{2}$ 
The main aim of TDM is to monitor drugs that show high variability in patients with different diseased conditions and drugs with narrow therapeutic windows so as to personalize the drug therapy accordingly. With the combined knowledge of pharmaceutics, pharmacokinetics and pharmacodynamics, the efficacy and the safety of a drug in diverse medical conditions can be appropriately assessed. 1

TDM has been increasingly proposed for many of the therapeutic drugs nowadays, e.g. antibiotics, tyrosine kinase inhibitors along with other targeted anticancer agents, TNF inhibitors, antifungal agents, antiretroviral agents that are used in HIV infection and also for psychiatric drugs ${ }^{3}$

The following are some examples of drugs that are widely analyzed for therapeutic drug monitoring: 4

- Aminoglycoside antibiotics (gentamicin)

- Mood stabilisers,

- Antiepileptics ( carbamazepine, phenytoin, valproic acid)

- Antipsychotics ( pimozide, clozapine)

- Cardiac glycosides (digoxin)

- Cyclosporin, tacrolimus used in organ transplant receiving patients.

There are many drugs with active metabolites or drugs that are given as prodrugs, where the parent compound has minimal or no pharmacological response. The pharmacological activity of such drugs is elicited by their metabolites. The drugs following the aforementioned mechanism make it difficult to obtain useful information from drug concentration measurements because it is the metabolites that show the therapeutic effect. Hence the active metabolites are assessed separately in these drugs and then monitored for their efficacy. ${ }^{5}$

Where there is a good indicator of drug efficacy, the need to measure drug concentrations is not necessary. For example: measuring the blood pressure during antihypertensive therapy or cholesterol levels in patients being treated with lipid lowering agents. The plasma concentration data for such drugs is very vital during their developmental stages so as to define their pharmacokinetic and pharmacodynamics parameters along with safety and efficacy. 5

Corticosteroids are used to treat a wide spectrum of inflammatory conditions as they provide rapid symptomatic relief and suppress inappropriate immune system activity. These are highly efficacious drugs and are mostly used to treat various autoimmune, respiratory \& dermatological conditions.

Corticosteroids are available in different types: Systemic and Localized.

Localized steroids: these steroids target a specific part of the body, although small amount of these steroids can be absorbed into the body. These can be applied as skin creams, eye drops, ear drops, or inhalers (for lungs). ${ }^{6}$

Systemic steroids: they can be given orally (tablets), through intravenous or intra muscular route(which can be into blood vessel, joints or muscles) to assist more parts of the body through the blood. ${ }^{7}$

Hydrocortisone and cortisone are termed as a naturally occurring corticosteroids released from the adrenal cortex. ${ }^{8}$

Systemic steroids are broadly divided into:
Glucocorticoids: it helps in the breakdown of fats, carbohydrates and proteins. Hence, reduces the inflammation and immunity.

Drugs include:

- Glucocorticoid

- Hydrocortisone

- Cortisone

- Prednisone

- Prednisolone

- Dexamethasone

Mineralocorticoids: Affects sodium, potassium and fluid balance.

Drugs include:

- fludrocortisone $^{9}$

These agents can cause various harmful side effects that are associated with excess dose and prolonged usage.

- Osteoporosis

- Skin atropy

- Diabetes

- Abdominal obesity

- Glaucoma

- Cataracts

- Hypertension ${ }^{10,11}$

Corticosteroids are mainly used to treat conditions such as:

- Asthma

- Allergic rhinitis and hay fever

- Urticarial (hives)

- Atopic eczema

- Chronic obstructive pulmonary disease (COPD)

- Painful and inflamed joints, muscles and tendons

- Lupus

- Inflammatory bowel disease (IBD) - including Crohn's disease and ulcerative colitis

- Giant cell arteritis and polymyalgia rheumatica

- Multiple sclerosis (MS)

They also treat Addison's diseases, in which the adrenal glands are unable to produce even the minimum amount of corticosteroids that the body needs. ${ }^{12}$

\section{MATERIALS AND METHOD}

The study included all the consecutive patients admitted to the hospital and those visited to hospital for follow up on the weekly or monthly basis with the age group more than 18 years of age.

Study Design: A Prospective Observational Study.

Study Site: General Medicine and Dermatology, Osmania General Hospital, Hyderabad.

Study Period: The study was carried out for a period of 6 Months.

Study Population: All the patients satisfying the inclusion criteria are being selected.

Sample SIZE: sample size is 100

Sources of Data:

$\checkmark$ Case Sheet

$\checkmark \quad$ Patient Interview

$\checkmark \quad$ Past Medication History 


\section{Study Criteria:}

Table 1: Inclusion and Exclusion Criteria:

\begin{tabular}{|l|l|}
\hline Inclusion Criteria & Exclusion Criteria \\
\hline Patients of Either Sex & Patients Suffering from terminal Illness \\
\hline Patients of Age Group > 18Yrs & Patients Suffering from Terminal Illness or Cancer \\
\hline Patients receiving corticosteroids for different indications. & Pregnant and Lactating women \\
\hline
\end{tabular}

\section{Plan of Work:}

Data collection form was designed, than after taking approval ethics committee, patient's data was collected prospectively by observations. Patient's progress and prescriptions were observed daily till his availability in the hospital. The data collected was analyzed for usage of corticosteroid along with other drugs in the prescriptions, duration of treatment was noted, the dosage form, the frequency of administration, inappropriate utilization of drug, drug- drug interactions and adverse drug reactions were observed and noted. Rationality of corticosteroids usage was also be analyzed as per standards provided in literature. Results are reported and conclusion is drawn.

$\checkmark$ Getting IEC approval

$\checkmark$ Designing of data collection form

$\checkmark$ Obtaining patients demographic data, previous medication and disease history

$\checkmark$ Recording of patients physical and physiological parameters

$\checkmark \quad$ Recording patients prescribed pharmacotherapy and follow up

$\checkmark$ Analyzing variations in the parameters with different drug therapies

$\checkmark \quad$ Percentage and graphical presentation of the results

$\checkmark$ Discussion

$\checkmark$ Conclusion.

\section{RESULTS}

This was a prospective observational study was conducted in the Out Patient Department of Osmania General Hospital in the In-patient Department of General Medicine for about 6 months. The results of the observations are reported below.

\section{Gender Distribution}

As per demographic data obtained, out of the total 100 patients, $68 \%$ were male and $32 \%$ were female. This data showed that commonly male population was more prone to diseases, for which steroids are used.
TABLE 2: DISRIBUTION OF SUBJECTS BASED ON GENDER

\begin{tabular}{|l|l|l|}
\hline Gender & No of Patients & Percentage Of Patients \\
\hline MALE & $\mathbf{6 8}$ & $68.00 \%$ \\
\hline FEMALE & $\mathbf{3 2}$ & $32.00 \%$ \\
\hline TOTAL & $\mathbf{1 0 0}$ & $100.00 \%$ \\
\hline
\end{tabular}

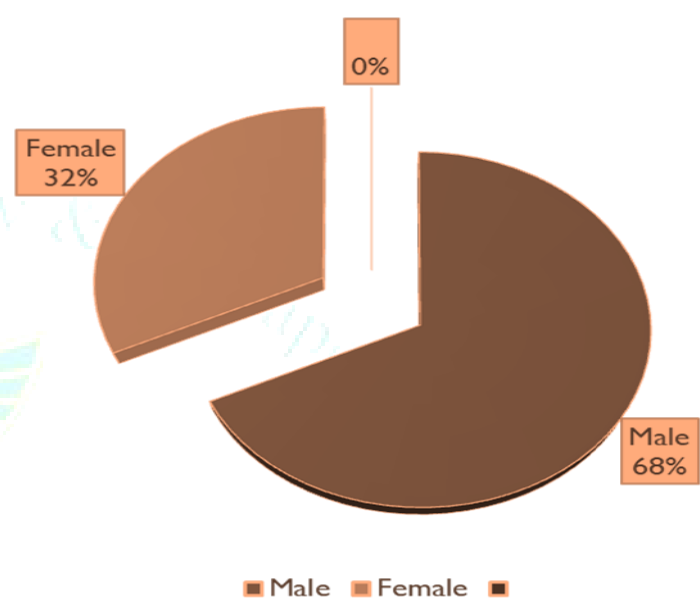

FIGURE-1: PIE CHART SHOWING DISTRIBUTION OF SUBJECTS BASED ON GENDER (\%)

\section{Age Distribution:}

All the patients were classified as per the age group a maximum of around $22 \%$ belongs to the age group of 59-68 and $20 \%$ belongs to the age group of 29-38 followed by least no of patients were found between the age group of $78-88$ and $89-98$ with the percentage of $3 \%$ and $1 \%$.

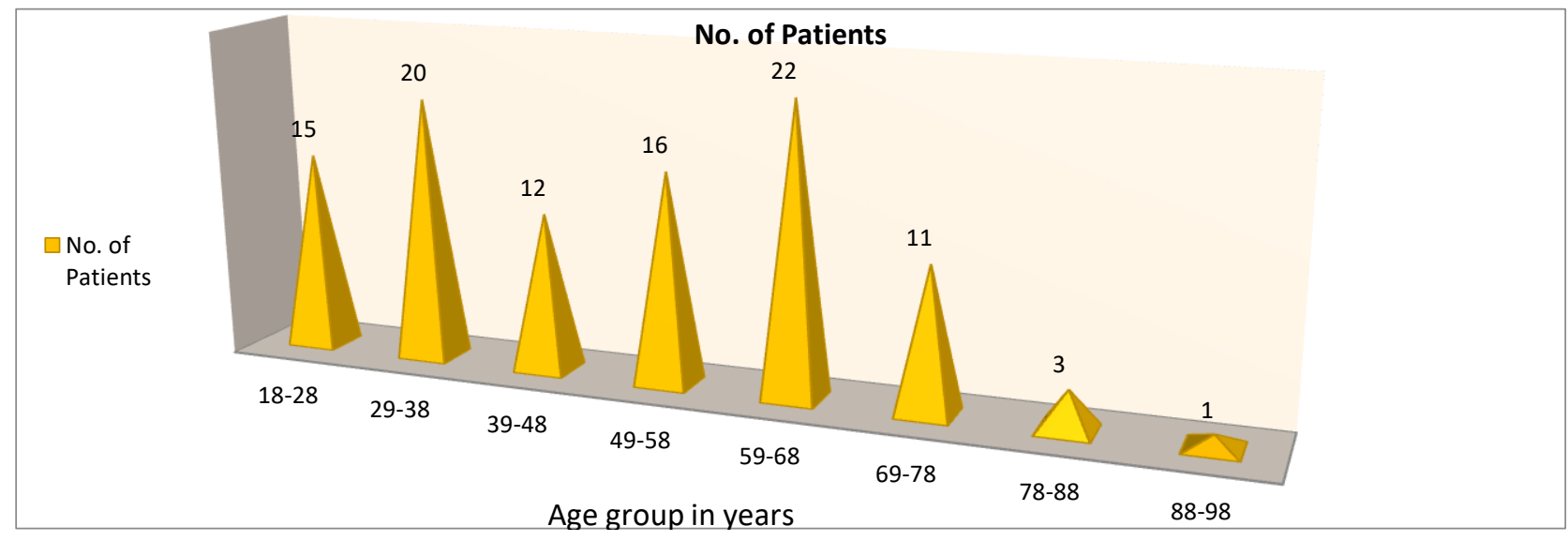

FIGURE-2: Showing distribution of subjects based on age 
Distribution of the Subjects on Usage of Steroids in Different Disease Conditions:

Systems involved with the usage of corticosteroid includerespiratory with the percentage of $40 \%$, neurology with the percentage of $15 \%$, cardiology with the percentage of $4 \%$, nephrology with the percentage of $2 \%$, endocrinology with the percentage of $2 \%$, dermatology with the percentage of $15 \%$, hepatology with the percentage of $1 \%$, skeletal system with the percentage of $2 \%$ and others with the percentage of $19 \%$. Among the study population the usage of corticosteroid was most common in respiratory system.

TABLE-3: Showing systems involved and usage of steroids

\begin{tabular}{|c|c|}
\hline SYSTEMS INVOLVED & No. of patients \\
\hline RESPIRATORY & 40 \\
\hline ASTHMA & 7 \\
\hline COPD & 21 \\
\hline TB & 6 \\
\hline PNEUMONITIS & 3 \\
\hline PLEURAL EFFUSION & 1 \\
\hline LUNG METASTASIS & 1 \\
\hline LEFT RESPIRATORY TRACT INFECTION & 1 \\
\hline NEUROLOGY & 15 \\
\hline AMS & 3 \\
\hline CVA & 4 \\
\hline EPILEPSY & 2 \\
\hline MENINGITIS & 4 \\
\hline OTHERS & 2 \\
\hline CARDIOLOGY & 4 \\
\hline CAD & 3 \\
\hline ANGIOEDEMA & 1 \\
\hline NEPHROLOGY & 2 \\
\hline AKI & 2 \\
\hline ENDOCRINOLOGY & 2 \\
\hline GRAVES DISEASE & 1 \\
\hline CUSHING SYNDROME & 1 \\
\hline DERMATOLOGY & 15 \\
\hline EXFOLIATIVE DERMATITIS & 1 \\
\hline SLE & 2 \\
\hline PSORIATIC ERYTHRODERMA & 6 \\
\hline HANSENS DISEASE & 4 \\
\hline SJS & 1 \\
\hline ALLERGIC CONTACT DERMATITIS & 1 \\
\hline HEPATOLOGY & 1 \\
\hline CLD & 1 \\
\hline SKELETAL SYSTEM & 2 \\
\hline MYESTHINIA GRAVIS & 1 \\
\hline POLYARTHRITIS & 1 \\
\hline $\begin{array}{l}\text { OTHERS } \\
\text { ANAEMIA, DVT, } \\
\text { SNAKE BITE, RADIAL NERVE PALSY, } \\
\text { IC BLEED WITH VASCULATION, } \\
\text { PARAQUIT POISONING, } \\
\text { THROMBOCYTOPENIA, PERIODIC PARALYSIS, } \\
\text { MCTD WITH VASCULITIS, DSAP, } \\
\text { ULCERATIVE COLITIS, CHRONIC URTICARIA, } \\
\text { ALOPECIAAREATA, } \\
\text { BULLOUS DISORDER, PEMPPHIGUS VULGARIS.BICYTOPENIA, ACUTE } \\
\text { FLACID QUADRAPERESIS, ACUTE NEUROLOGICAL ILLNESS. }\end{array}$ & 19 \\
\hline
\end{tabular}




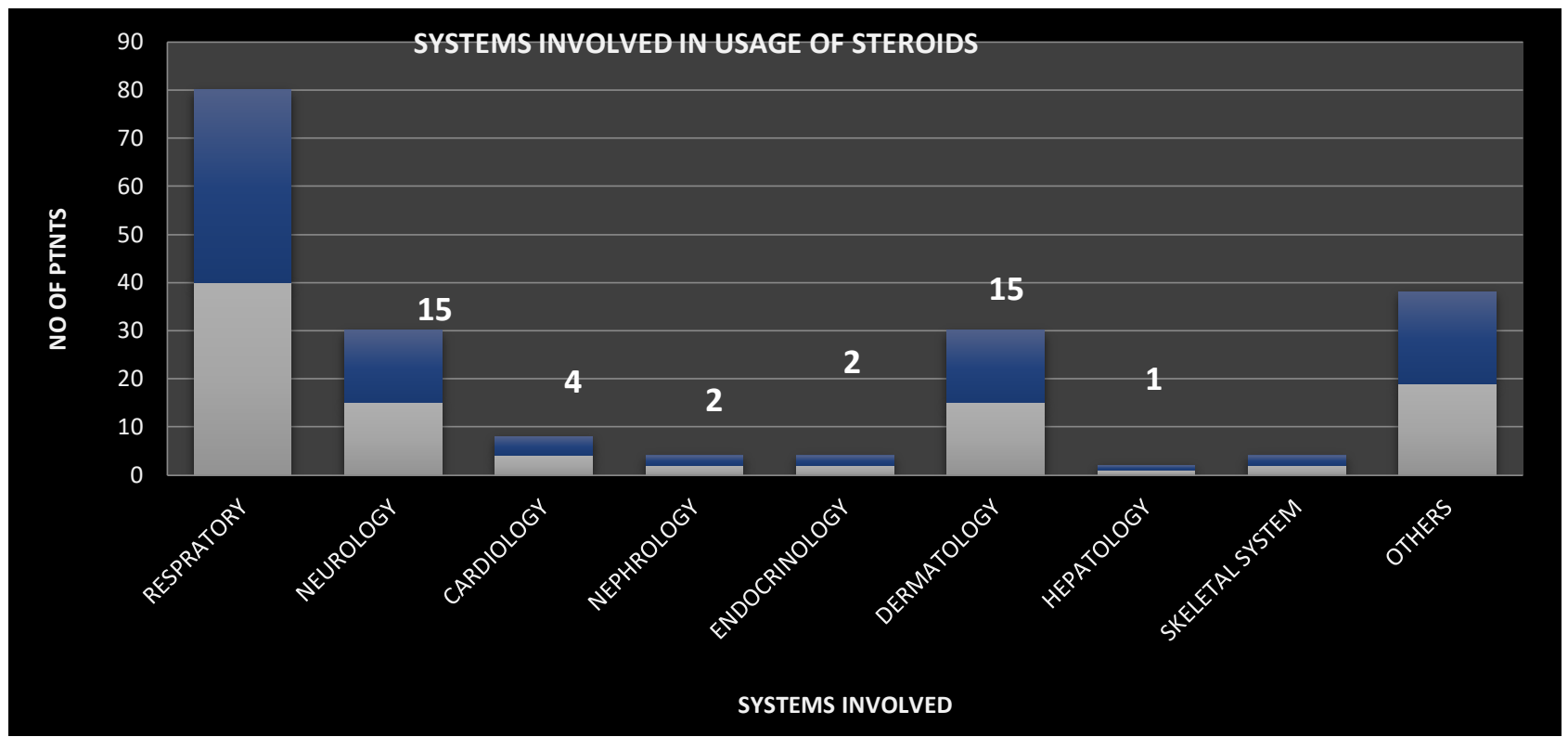

FIGURE-3: Showing systems involved and usage of steroids

Among the study Population the diseases involved include with the systems Include

Respiratory system: It include diseases such as Asthma with the percentage of $7 \%$, COPD with the percentage of $21 \%$, tb with the percentage of $6 \%$, pneumonitis with the percentage of $3 \%$, pleural effusion with the percentage of $1 \%$, lung metastasis with the percentage of $1 \%$, left respiratory tract infection with the percentage of $1 \%$.

Neurology: It include diseases such as AMS with the percentage of $3 \%$, CVA with the percentage of $4 \%$, epilepsy with the percentage of $2 \%$, meningitis with the percentage of $4 \%$, others with the percentage of $2 \%$.

Cardiology: It includes diseases such as cad with the percentage of $3 \%$, angioedema with the percentage of $1 \%$.

Nephrology: It includes diseases such as Acute kidney injury with the percentage of $2 \%$.

Endocrinology: It includes diseases such as graves' disease with the percentage of $1 \%$, Cushing syndrome with the percentage of $1 \%$.

Dermatology: It include diseases such as exfoliative dermatitis with the percentage of $1 \%$, SLE with the percentage of $2 \%$, psoriatic erythroderma with the percentage of $6 \%$, Hansen's disease with the percentage of
$4 \%$, SIS with the percentage of $1 \%$, allergic contact dermatitis with the percentage of $1 \%$.

Hepatology: It includes diseases such as CLD with the percentage of $1 \%$.

Skeletal System: It includes diseases such as myasthenia gravis with the percentage of $1 \%$, polyarthritis with the percentage of $1 \%$.

Others: It include diseases such as anaemia, DVT, snake poisoning, radial nerve palsy, TC bleed with vesiculation, paraquat poisoning, thrombocytopenia, periodic paralysis, MCTD with vasculitis, ulcerative colitis, chronic urticaria, alopecia areata, DSAP, bullous disorder, pemphigus vulgaris, bi cytopenia, acute flaccid quadriparesis, acute neurological illness.

\section{Distribution of Different Types of Steroids Prescribed to the Patients:}

Among the study population the corticosteroid prescribed to patients include prednisolone, hydrocortisone, methyl prednisolone, budesonide, dexamethasone, betamethasone with the percentages as $13.49 \%, 26.19 \%, 5.56 \%$, $31.75 \%, 15.08 \%, 7.94 \%$ among these the mostly prescribed corticosteroid is budesonide with the percentage of $31.75 \%$ and the least prescribed corticosteroid is methyl prednisolone with the percentage of $5.56 \%$.

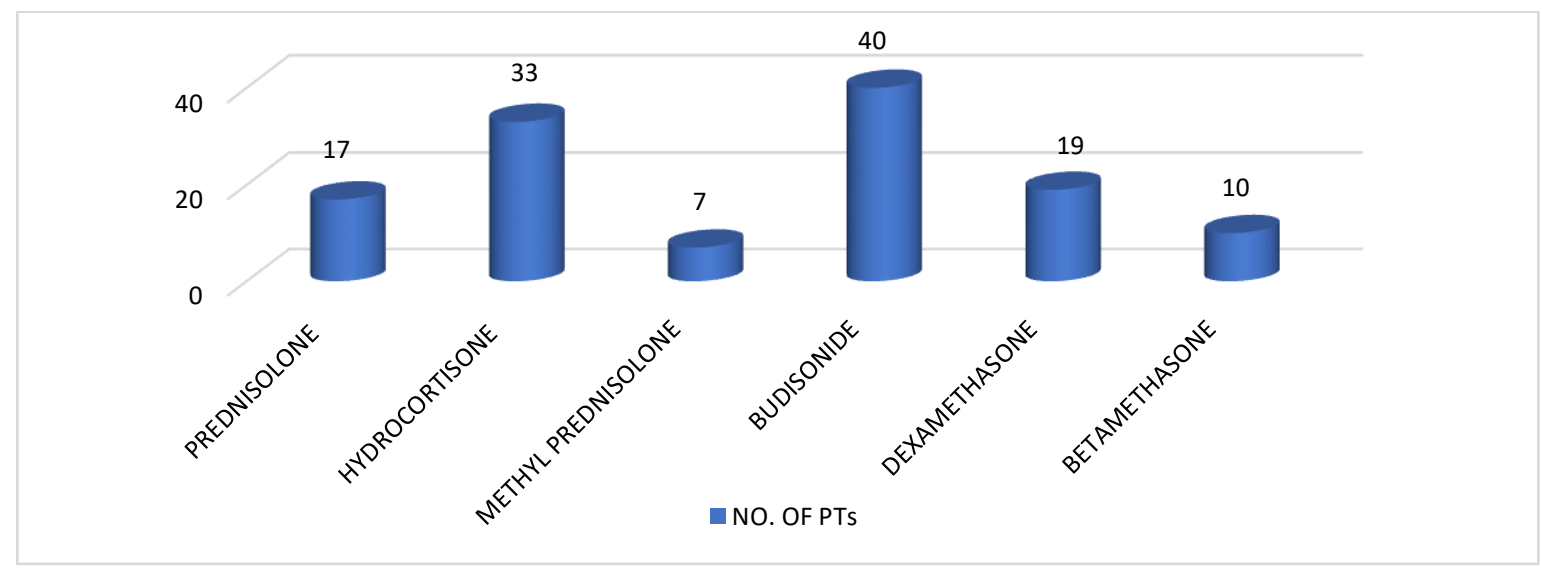

FIGURE-4: Showing distribution of steroids prescribed to subjects. 


\section{Steroids Studied For Drug Utilization Review:}

\section{Indications, Dose, Dosage of Corticosteroid usage:}

Prednisolone: Prednisolone was prescribed to 17 patients in our study in indications such as anti-inflammatory conditions 5 , autoimmune diseases. It was given by the route oral and IV and in dosage of $20 \mathrm{mg}$ and $40 \mathrm{mg}$.

Hydrocortisone: Hydrocortisone was prescribed to 33 patients in our study in indications such as community acquired pneumonia. It was given by the route IV and in dosage of $100 \mathrm{mg}$

Methyl prednisolone: Methyl prednisolone was prescribed to 7 patients in our study in indications such as rheumatoid arthritis and dermatitis. It was given by the route IV and in dosage of $1 \mathrm{~g}$ in $100 \mathrm{ml} \mathrm{ns}$

Budesonide: Budesonide was prescribed to 40 patients in our study in indications such as shortness of breath. It was given by the route intranasal and in dosage of $0.2 \mathrm{mg}$.

Dexamethasone: Dexamethasone was prescribed to 19 patients in our study in indications such as antiinflammatory conditions. It was given by the route oral, IV and in dosage of $8 \mathrm{mg}$

Betamethasone: Betamethasone was prescribed to 10 patients in our study in indications such as dermatitis. It was given by topical route.

Table 4: Indications, Dose, Dosage of Corticosteroid Usage:

\begin{tabular}{|c|c|c|c|c|}
\hline SNO & $\begin{array}{l}\text { NAME OF THE } \\
\text { DRUG }\end{array}$ & INDICATION & DOSAGE FORM & DOSE USED \\
\hline & & $\begin{array}{lll}\text { INFLAMMATORY } & \text { CONDITIONS, } & \text { AUTOIMMUNE } \\
\text { DISEASES } & & \end{array}$ & \multirow{2}{*}{ PO AND IV } & \multirow{2}{*}{$20,40 \mathrm{MG}$} \\
\hline 1 & Prednisolone & $\begin{array}{l}\text { Prednisolone was prescribed to } 17 \text { patients } .5 \text { as } \\
\text { anti-inflammatory, } 12 \text { for autoimmune diseases }\end{array}$ & & \\
\hline \multirow[t]{2}{*}{2} & Hydrocortisone & CAP & \multirow[t]{2}{*}{ IV } & \multirow[t]{2}{*}{$100 \mathrm{MG}$} \\
\hline & & $\begin{array}{l}\text { Hydrocortisone was prescribed to } 33 \text { patients. } 3 \text { for } \\
\text { CAP and 30to treat breathing problems }\end{array}$ & & \\
\hline \multirow[t]{2}{*}{3} & Methyl & DERMATITIS & \multirow[t]{2}{*}{ IV } & \multirow[t]{2}{*}{$1 \mathrm{G}$ in $100 \mathrm{ml} \mathrm{NS}$} \\
\hline & Preanisolone & $\begin{array}{l}\text { Methyl prednisolone was prescribed to } 7 \text { patients. } 2 \\
\text { for blood disorders and } 5 \text { to treat allergic reactions }\end{array}$ & & \\
\hline \multirow[t]{2}{*}{4} & Budesonide & SOB & \multirow[t]{2}{*}{ IN } & \multirow[t]{2}{*}{$0.2 \mathrm{MG}$} \\
\hline & & $\begin{array}{l}\text { Budesonide was prescribed to } 40 \text { patients to treat } \\
\text { SOB }\end{array}$ & & \\
\hline \multirow[t]{2}{*}{5} & Dexamethasone & ANTI INFLAMMATORY & \multirow[t]{2}{*}{ PO \& IV } & \multirow[t]{2}{*}{$8 \mathrm{MG}$} \\
\hline & & $\begin{array}{l}\text { Dexamethasone was prescribed to } 19 \text { patients as } \\
\text { anti-inflammatory agent }\end{array}$ & & \\
\hline \multirow[t]{2}{*}{6} & Betamethasone & DERMATITIS & \multirow[t]{2}{*}{ TOPICAL } & \multirow{2}{*}{$\begin{array}{l}\text { LOCAL } \\
\text { APPLICATION }\end{array}$} \\
\hline & & $\begin{array}{l}\text { Betamethasone was prescribed to } 10 \text { patients for } \\
\text { skin diseases }\end{array}$ & & \\
\hline
\end{tabular}

\section{Duration of Treatment}

The study was conducted on subjects for the treatment duration of 1 week followed by 2 week $77 \%$ subjects were treated for the duration of 1 week, \& $23 \%$ subjects were treated for the duration of 2 weeks.

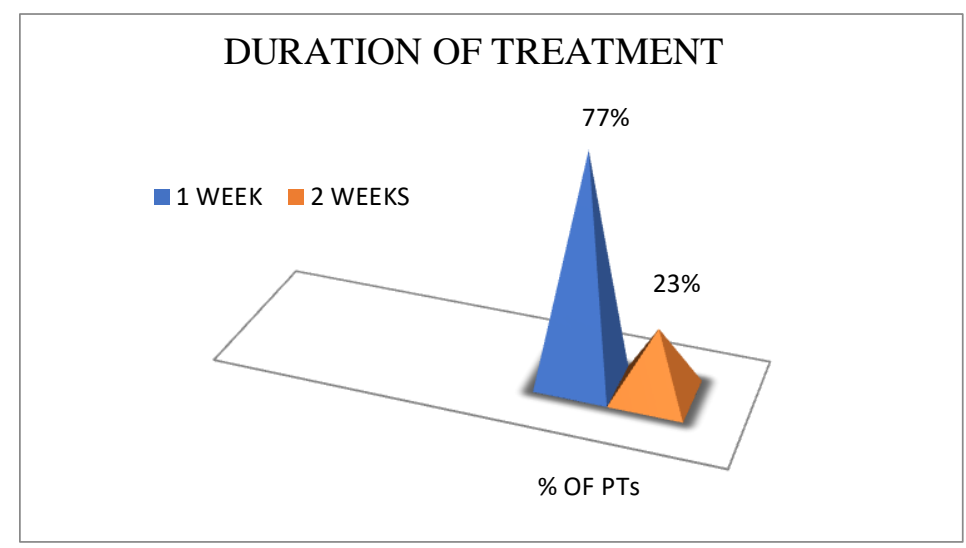

FIGURE-5: Showing duration of treatment of subjects 


\section{Drug-Drug Interaction in Study Population:}

The study was conducted on a study population of 100 subjects and drug-drug interactions were checked on software Micromedex \& out of 100 subjects 1 drug-drug interaction were found to be severe this 1 interaction were noted \& 24 minor interactions were noted in the department general medicine \& 0 interaction were noted in the department of dermatology.

Table 5: Showing drug-drug interaction in a study population

\begin{tabular}{|l|c|c|}
\hline \multicolumn{3}{|c|}{ DRUG DRUG INTERACTION } \\
\hline & MAJOR & MINOR \\
\hline GENERAL MEDICINE & 1 & 24 \\
\hline DERMATOLOGY & 0 & 0 \\
\hline
\end{tabular}

\section{Drug-Drug Interaction Found:}

Table 6: Severe drug-drug interaction found in the study

\begin{tabular}{|l|l|}
$\begin{array}{l}\text { Rifampicin } \\
\text { (Antitubercular) }+ \\
\text { Dexamethasone }\end{array}$ & $\begin{array}{l}\text { Rifampicin will decrease the level or effect of dexamethasone by affecting hepatic or intestinal enzyme } \\
\text { CYP3A4 metabolism. Possible serious or life-threatening interaction. Monitor closely. Use alternatives } \\
\text { if available. Also, rifampin will decrease the level or effect of dexamethasone by P-glycoprotein efflux } \\
\text { transporter. Significant interaction possible, monitor closely. }\end{array}$ \\
\hline
\end{tabular}

\section{Adverse Drug Reactions with Corticosteroid Usage:}

In this study Adverse drug reactions were reported by patients for ten instances that account for six different types of adverse effects as mentioned below in table, noted mainly by three corticosteroids were found to be the cause of adverse drug reaction. Prednisolone caused headache in 2 patients, facial mooning in 2 patients, osteoarthritis in 1 patient. Dexamethasone caused headache in 1 patient, hypertension in 1 patient, hyperglycaemia in 1 patient, hydrocortisone caused hypertension in 2 patients.

Table 7: adverse drug reaction found in the study

\begin{tabular}{|l|l|l|}
\hline Drug & ADR observed & NO. of cases \\
\hline Prednisolone & Headache & 2 \\
& Facial mooning & 2 \\
& osteoarthritis & 1 \\
\hline Dexamethasone & Headache & 1 \\
& Hypertension & 1 \\
& Hyperglycemia & 1 \\
\hline Hydrocortisone & Hypertension & 2 \\
\hline
\end{tabular}

\section{DISCUSSION}

- In this study 100 Patients were included with different Morbidity who were admitted and prescribed Corticosteroids in various inpatient department of Osmania General Hospital. Demography, route of administration, corticosteroid used, dose and dose frequency, condition for use, drug interactions and ADRs subsequent to use of corticosteroids were studied.

- $\quad$ This study included 100 Patients out of which 68 (68\%) were Male and 32 (32\%) were female. This data showed that commonly male population are more prone to diseases, for which steroids are used. It shows that corticosteroids are mainly used between the age group of 22 (22\%) 59-68 years. As this Age group consider to be mostly affected with many Inflammatory and chronic diseases. We observed that as the age group increased the prescribing of corticosteroids has also been more frequent.

- As per the demographic data our finding shows that Budesonide was the most frequent prescribed corticosteroid (31.75\%) followed by Hydrocortisone (26.19\%), Dexamethasone (15.08\%), Prednisolone $13.49 \%$, Betamethasone (7.94\%), Methyl prednisolone (5.56\%). Here Budesonide was mostly used steroid.

- System Associated with the use of Corticosteroids are Respiratory, Neurological, Dermatological with a percentage of $36 \%, 21 \%, 18 \%$ respectively.

- In our study Prednisolone is used for the treatment of Inflammatory conditions and Auto Immune diseases, route of administration is oral and IV with the dosage 20, 40mg. Hydrocortisone for CAP, route (IV), Dose $100 \mathrm{mg}$. Methylprednisolone for RA and Dermatitis, route (IV), dose $10 \mathrm{mg}$. Budesonide for SOB, route Inhalation (IN), dose $0.2 \mathrm{mg}$. Dexamethasone for AntiInflammatory conditions, route (oral and IV), dose 8mg.

- A Drug-Drug Interaction (Rifampicin + Dexamethasone) is noted in two patients. The patients lied in the age group of 60-70 Years, probably due to co-morbidities and more corticosteroids usage to have broad beneficial effect in older age population.

- In 100 prescriptions total 25 interactions were found out of which 24 were minor, 1 were major. Mostly minor interactions were found in the study which was consistent with the study Imran, et al.who found that $24 \%$ of the interactions were minor, $1 \%$ were major were contraindicated interactions subsequent the use of corticosteroids in his study.

- Ten ADRs were found in this study due to corticosteroids use. Facial mooning was detected in 2, headache in 3 , hyperglycaemia in 1 , hypertension in 3 (25\%) and osteoporosis in $1(12.50 \%)$. Our study was consistent with the study of Treadwell.B, et al 12. WHO found that corticosteroid causes hypertension, facial mooning, osteoporosis in the subjects who were on corticosteroid therapy, Also Clore J, et al.13 in his study 
found that Glucocorticoid-induced hyperglycaemia is common in patients with and without diabetes

\section{CONCLUSION:}

Corticosteroids are widely prescribed Drugs in Hospitals, forming a part of standard treatment of modern medicine for a wide range of diseases, which associated with inflammation and immune activation. Apart from beneficial effects they also produce number of adverse effects.

In the present study, Prospective Observational studies on DUE and rationality of Corticosteroids has been performed. Out of 100 prescriptions total 10 ADRs and 25 Drug interactions were detected in this study. The majority of drug interactions were minor $24(24 \%)$ followed by major $1(1 \%)$.

Most of the prescription were found to be rational some of them were found to be irrational as there were significant drug interactions. Commonly a patient between the age group of 59-68 years was more prone to diseases, for which steroids were used. Hence close observation is required.

To ensure safety, effectiveness and well-balanced therapeutic management with corticosteroids, both patients and prescribers should be more aware of the appropriate dose, dosage regimen, with careful monitoring of ADRs and Drug - drug interactions.

Hence, the clinical pharmacist can perform potential role in health care system in assisting physician in altering the number of medications taken, the number of doses taken, improving the patient medication adherence, preventing the adverse drug reactions, Drug - Drug interactions, in patient counselling, improve the health-related quality of life and decreasing the health care cost of the patient.

Till now, effective treatment guidelines for corticosteroids are not available. Even though we can't completely eliminate the occurrence of ADRs, definitely we can minimize it. Further studies are needed for implementing standard Guidelines in corticosteroid therapy and all hospitals should implement steroid treatment card to improve the quality of life of the patients.

\section{ABBREVIATIONS}

\begin{tabular}{|l|l|}
\hline ADR & Adverse drug reaction \\
\hline COPD & $\begin{array}{l}\text { Chronic obstructive pulmonary } \\
\text { disease }\end{array}$ \\
\hline CYP3A4 & Cytochrome P450 Enzyme \\
\hline DNA & Deoxyribose Nucleic Acid \\
\hline DVT & Deep vein thrombosis \\
\hline DUE & Drug utilization evaluation \\
\hline HIV & Human immune deficiency virus \\
\hline IBD & Inflammatory bowel disease \\
\hline IV & Intra venous \\
\hline IN & Inhalation \\
\hline MS & Multiple sclerosis \\
\hline TNF & Tumor necrosis factor \\
\hline
\end{tabular}

\section{REFERENCES}

1. Kang, J.-S., \& Lee, M.-H. Overview of Therapeutic Drug Monitoring. The Korean Journal of Internal Medicine, 2009; 24(1):1. doi:10.3904/kjim.2009.24.1.1

2. Gross AS, Blackwell Science Ltd Br J Clin Pharmacol, 2001 ; 52:5S-10S

3. Schoretsanitis G et al. (April 2018). "TDM in psychiatry and neurology: A comprehensive summary of the consensus guidelines for therapeutic drug monitoring in neuropsychopharmacology, update 2017; a tool for clinicians". World Journal of Biological Psychiatry. 19 (3): 162-174.

4. Marshall WJ, Bangert SK. Clinical Chemistry, 6th Edition. Edinburgh, London: Mosby Elsevier. 2008. ISBN 9780723434559

5. Hallworth M, in Clinical Biochemistry: Metabolic and Clinical Aspects (Third Edition), 2014, Pages 767-786

6. Ramamoorthy S, Cidlowski JA, Corticosteroids-Mechanisms of Action in Health and Disease Rheum Dis Clin North Am. 2016; 42(1): 15-31

7. William Ericson-Neilsen, MD, Alan David Kaye, MD, PhD Steroids: Pharmacology, Complications, and Practice Delivery Issues. Academic Division of Ochsner Clinic Foundation the Ochsner Journal 2014; 14:203-207.

8. Safiya Shaikh et al., Applications of Steroid in Clinical Practice: A Review. International Scholarly Research Network ISRN Anaesthesiology 2012, Article ID 985495, 11 pages.

9. Liu et al A practical guide to the monitoring and management of the complications of systemic corticosteroid therapy, Allergy, Asthma \& Clinical Immunology 2013, 9:30

10. National Institute for Health and Clinical Excellence (NICE): Clinical Knowledge Summaries: Corticosteroids - Oral. NICE; 2012. [http://www.cks.nhs. uk/corticosteroids_oral], Accessed February 20, 2013.

11. Singh N, Rieder MJ, Tucker MJ: Mechanisms of glucocorticoidmediated antiinflammatory and immunosuppressive action. Paed Perinatal Drug Ther 2004, 6:107-115.

12. Newton R, Leigh R, Giembycz MA: Pharmacological strategies for improving the efficacy and therapeutic ratio of glucocorticoids in inflammatory lung diseases. Pharmacol Ther 2010, 125:286-327.

13. Coutinho AE, Chapman KE: The anti-inflammatory and immunosuppressive effects of glucocorticoids, recent developments and mechanistic insights. Mol Cell Endocrinol 2011, 335:2-13.

14. Croxtall JD, van Hal PT, Choudhury Q, Gilroy DW, Flower RJ: Different glucocorticoids vary in their genomic and nongenomic mechanism of action in A549 cells. Br J Pharmacol 2002, 135:511-519.

15. Smoak KA, Cidlowski JA: Mechanisms of glucocorticoid receptor signaling during inflammation. Mech Ageing Dev 2004, 125:697-706.

16. Stellato C: Post-transcriptional and nongenomic effects of glucocorticoids. Proc Am Thorac Soc 2004, 1:255-263.

17. Furst DE, Saag KG: Determinants of glucocorticoid dosing, Up To Date 2012; 2013. http://www.uptodate.com/contents/determinants-of glucocorticoiddosing?source=search_result \&search=glucocort icoid\&selectedTitle $=4 \sim 150$.

18. Deshmukh CT: Minimizing side effects of systemic corticosteroids in children. Indian J Dermatol Venereol Leprol 2007, 73:218-221.

19. Da Silva JA, Jacobs JW, Kirwan JR, Boers M, Saag KG, Inês LB, de Koning EJ, Buttgereit F, Cutolo M, Capell H, Rau R, Bijlsma JW: Safety of low dose glucocorticoid treatment in rheumatoid arthritis: published evidence and prospective trial data. Ann Rheum Dis 2006, 65:285-293.

20. Weinstein RS, Jilka RL, Parfitt AM, Manolagas SC: Inhibition of osteoblastogenesis and promotion of apoptosis of osteoblasts and osteocytes by glucocorticoids. Potential mechanisms of their deleterious effects on bone. J Clin Invest 1998, 102:274282. 